\title{
Fluctuations in neurofibrillary tangle density in Alzheimer's disease revealed by Fourier (spectral) analysis
}

\author{
Richard Armstrong \\ Vision Sciences, Aston University, Birmingham, United Kingdom
}

Folia Neuropathol 2020; 58 (4): 299-306
DOI: https://doi.org/10.5114/fn.2020.102432

\begin{abstract}
Significant densities of neurofibrillary tangles (NFT) often occur in regions of the cerebral cortex and hippocampus in cases of Alzheimer's disease (AD). To investigate the spatial fluctuations of NFT in these regions, variations in the density of Gallyas-stained NFT were recorded in 'transects' of contiguous sample fields aligned parallel with the tissue boundary. Fourier (spectral) analysis was used to analyse the fluctuations in density of NFT and to interpret them in relation to the underlying neuroanatomy. The Fourier analysis suggested that NFT exhibited complex sinusoidal fluctuations in density in the cerebral cortex and hippocampus in $A D$. The fluctuations occurred at different scales, the most common pattern being a small-scale sinusoidal fluctuation repeating every 500-1000 $\mu \mathrm{m}$ and a larger-scale pattern repeating at distances greater than $1000 \mu \mathrm{m}$. These fluctuations in density may reflect the association of NFT with the modular structure of the cortex and hippocampus. Fourier analysis may be a useful statistical method for studying the patterns of NFT and other abundant cellular inclusions in neurodegenerative disease.
\end{abstract}

Key words: Fourier (spectral) analysis, neurofibrillary tangles (NFT), spatial pattern.

\section{Introduction}

The presence of extracellular senile plaques (SP) and intracellular neurofibrillary tangles (NFT), which contain deposits of $\beta$-amyloid $(A \beta)[16]$ and phosphorylated microtubule associated protein (MAP) tau [17], respectively, are the 'signature' pathological features of AD $[22,24]$. In the cortex and hippocampus of patients with $A D$, regularly repeating patterns of A $\beta$ deposits [1] and NFT [5,19] have been observed in a direction parallel to the tissue boundary. These variations in density may reflect the degeneration of specific anatomical features $[13,19,27]$, and studies of the spatial patterns of $A \beta$ deposits and NFT are potentially useful in elucidating the relationship between the pathological changes, the modular structure of the cortex $[1,8]$, and the cerebral microvasculature [4].

In previous studies of the spatial patterns of brain lesions, the densities of NFT were recorded in 'transects' of contiguous sample fields aligned parallel with the tissue boundary [3]. The frequency distribution of the lesion densities in the sample fields was then compared with that predicted by the Poisson distribution; a variance/mean (V/M) ratio of the data less than or greater than unity indicating departures from randomness towards regularity or clustering, respectively $[1,2]$. Counts of lesions in adjacent sample fields may then be added together successively to provide data for larger field sizes,

Communicating author

Dr. Phil. Richard Armstrong, Vision Sciences, Aston University, Aston Street, B4 7ET, Birmingham, United Kingdom,

phone: +441212044102, e-mail: R.A.Armstrong@aston.ac.uk 
thus enabling cluster sizes to be estimated and the distribution of the clusters parallel to the tissue boundary to be determined [1].

Methods of spatial pattern analysis based on the Poisson distribution have a number of limitations [8]. First, the method can only be used to analyse counts of a lesion or 'density data' and not alternative measures of abundance such as 'coverage' or 'load' [3,9]. Second, a linear trend in the abundance of lesions parallel to the tissue boundary, or the presence of a single large cluster occupying a significant portion of a region, can make it difficult to detect smaller-scale clustering patterns [9]. Third, the method may not estimate cluster size accurately enough to be able to relate spatial patterns of a pathology to neuroanatomical features $[1,2,5]$. Fourth, in many cases of AD, NFT are present at high density, are not distributed in discrete clusters, and may exhibit a more continuous fluctuating pattern of abundance along cortical gyri parallel to the pia mater. Fifth, fluctuations in density may repeat at several different scales, and these more complex patterns are not well detected using the Poisson method [9].

Bruce et al. [12] were among the first authors to suggest that Fourier (spectral) analysis might be used to examine the laminar distribution of $A \beta$ deposits across the cortex from pia mater to white matter in AD [14]; a method subsequently used in the same disorder to analyse changes in $A \beta$ deposit density parallel to the pia mater [9]. Fourier analysis attempts to understand the pattern of fluctuations of a quantity in space or time (the 'signal') by breaking it down into simpler sine waves. The original signal comprises sine waves of different frequency corresponding to fluctuations repeating at different scales, the sine waves being easier to study and interpret than the original more complex signal. The method has been applied in many scientific fields including physics, mathematics, imaging, probability theory, and acoustics [30,31]. Hence, the objective of the present study was to determine the spatial fluctuations in NFT density in the cerebral cortex and hippocampus, measured parallel to the pia mater or alveus, respectively, and which constitute the 'signal'. The analysis identifies the sine waves that comprise the frequency components of the NFT fluctuations, and these frequency components may then be interpreted in relation to the underlying neuroanatomical features of the cerebral cortex and hippocampus [9].

\section{Material and methods}

\section{Cases}

Six cases of sporadic AD (details in Table I), with particularly high densities of NFT, were obtained from the Brain Bank, Department of Neuropathology, Institute of Psychiatry, King's College, London, UK. Informed consent was given for the removal of all tissue and the study followed the principles embodied in the 1964 Helsinki Declaration (as modified Edinburgh, 2000). Post-mortem delay was less than 20 hours in each case. The AD cases were clinically assessed, and all fulfilled the 'National Institute of Neurological and Communicative Disorders and Stroke and Alzheimer's Disease and Related Disorders Association' (NINCDS/ADRDA) criteria for probable AD [34]. The histological diagnosis of $A D$ was established by the presence of widespread neocortical SP consistent with the 'Consortium to Establish a Registry of Alzheimer's Disease' (CERAD) criteria [24] and 'National Institute on Aging (NIA)-Reagan Institute' criteria [21]. The apolipoprotein E (APOE) genotype of the $A D$ cases, an important risk factor

Table I. Demographic data, cause of death, Braak disease stage, National Institute on Aging-Alzheimer's association (NIA-AA) 'B score', and apolipoprotein E (APOE) genotype of the Alzheimer's disease cases used in the study ( $M$ - male, $F-$ female)

\begin{tabular}{|c|c|c|c|c|c|c|c|}
\hline Case & Sex & Age & Onset & Cause of death & $\begin{array}{l}\text { Braak } \\
\text { stage }\end{array}$ & $\begin{array}{l}\text { NIA-AA } \\
\text { 'B' score }\end{array}$ & APOE \\
\hline$A$ & $\mathrm{~F}$ & 91 & 85 & Bronchopneumonia & $\mathrm{VI}$ & 3 & $3 / 4$ \\
\hline B & $\mathrm{F}$ & 86 & 83 & Bronchopneumonia & VI & 3 & $3 / 4$ \\
\hline C & $\mathrm{F}$ & 85 & 80 & Bronchopneumonia & VI & 3 & $4 / 4$ \\
\hline D & $\mathrm{F}$ & 88 & 72 & Bronchopneumonia & VI & 3 & $3 / 4$ \\
\hline E & $\mathrm{F}$ & 81 & 77 & Bronchopneumonia & V & 3 & $3 / 4$ \\
\hline $\mathrm{F}$ & $\mathrm{F}$ & 93 & 91 & Bronchopneumonia & $\mathrm{VI}$ & 3 & $4 / 4$ \\
\hline
\end{tabular}


for $A D$, was either $3 / 4$ or 4/4 and the cases represented pathological stages $\mathrm{V}$ or $\mathrm{VI}$ of the Braak staging system $[10,11]$. In addition, all cases had NFT (B scores) of 3 as assessed using the National Institute on Aging-Alzheimer's association (NIA-AA) guidelines [20,25].

\section{Tissue preparation}

Blocks were taken from: 1) the frontal lobe, to study the superior frontal gyrus (SFG) (BA 8,6); 2) the parietal lobe, to study the superior parietal lobe (SPL) (BA 7); 3) the occipital lobe (OC), to study the primary and secondary visual cortex (BA 17,18); and 4) the temporal cortex, to study the superior temporal gyrus (STG) (BA 38), lateral occipitotemporal gyrus (LOT) (BA 35), parahippocampal gyrus (PHG) (BA 28), sectors CA1-4 of the hippocampus, and dentate gyrus (DG). Tissue was fixed in 10\% phosphate-buffered formal-saline and embedded in paraffin wax. 7- $\mu \mathrm{m}$ coronal sections were stained using the Gallyas silver-impregnation method [15], which reveals the cellular NFT particularly clearly (Fig. 1) [6]. The Gallyas stain has high sensitivity for detecting argyrophilic inclusions in cell bodies [23,33], PHF-1 and immunolabelling methods being less sensitive than the Gallyas method, and improved thioflavin-S stains [33]. In addition, the background staining associated with the Gallyas method enables recognition of anatomical landmarks and cytomorphology. The Gallyas stain is less useful, however, in studying the pathology in fine processes or in axon terminals.

\section{Morphometric methods}

In cortical gyri, with particularly high numbers of NFT, variation in density was studied from the crest to the base of a sulcus parallel to the pia mater, using two hundred 1000- $\mu \mathrm{m}$ sample fields arranged contiguously [3]. The sample fields were located in the upper cortex, approximating to layers II/III where AD pathology is most dense, although NFT pathology also occurs in lower cortical layers [5]. The short edge of the sample field was orientated parallel with the pia mater and aligned with guidelines drawn on the section. In the hippocampus, the sample fields were aligned initially with the alveus, and the pyramidal cell layer from sectors CA1 to CA3 were studied. Measurements were continued into sector CA4 using a guideline marked on the slide and which ceased approximately $400 \mu \mathrm{m}$ from the dentate gyrus granule cell layer.

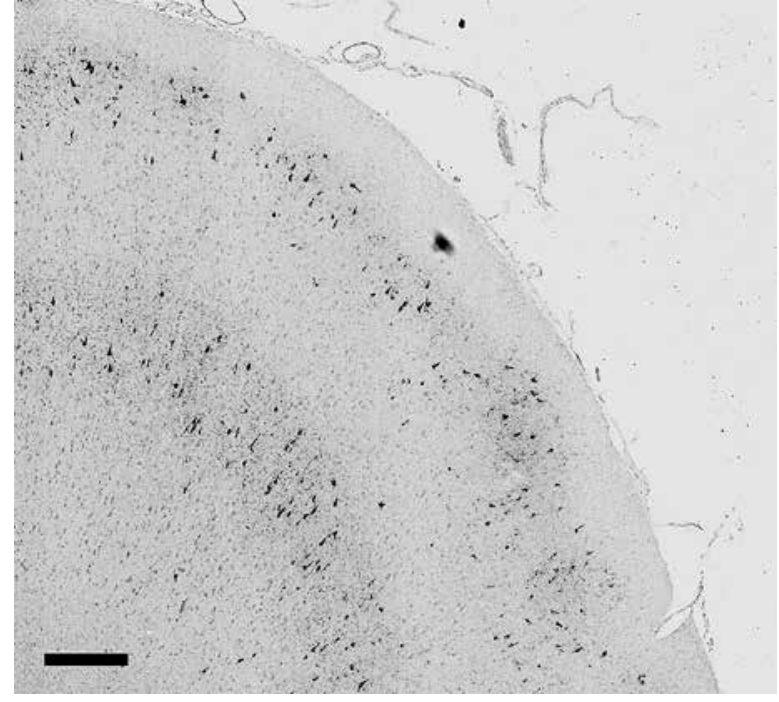

Fig. 1. Fluctuating patterns of darkly stained neurofibrillary tangles (NFT) distributed along the frontal cortex in the upper and lower layers of the cortex in a case of Alzheimer's disease (AD). Fourier analysis was carried out on the NFT in the upper cortical layers (Gallyas silver stain, Bar $=100 \mu \mathrm{m})$.

\section{Data analysis}

The data were analysed by single-spectrum (Fourier) analysis [30,31] using STATISTICA software (StatSoft Inc., 2300 East 14 ${ }^{\text {th }}$ St, Tulsa, Ok, 74104, USA). The analysis was applied to the NFT in each gyrus and hippocampus studied from each AD case with sufficient densities of NFT (a total sample of 36 regions). First, variations in the density of NFT along the gyri and CA region were examined for a linear trend. If such a trend was present, it might have obscured smaller-scale patterns, so the data were then 'corrected' to remove the effect of this linearity [9]. Second, the data from each region were tested to determine whether there were any statistically significant sinusoidal fluctuations present. If the fluctuations in density parallel to the tissue boundary were simply random 'noise', then the raw periodogram values (spectral densities) would follow an exponential distribution. Hence, the exponential distribution was fitted to the frequency distribution of periodogram values and goodness-offit tested using the Kolmogorov-Smirnov (KS) test [9]. Third, if the data deviated from an exponential distribution, significant recurring sinusoidal patterns were present, and the periodogram values 


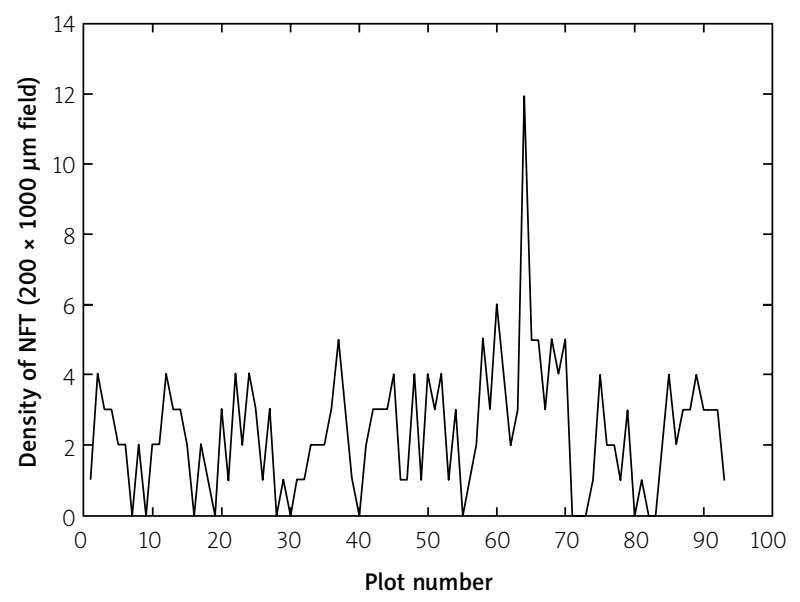

Fig. 2. The fluctuating density (number of deposits per $200 \times 1000 \mu \mathrm{m}$ plot) of the neurofibrillary tangles (NFT) parallel to the pia mater along the upper laminae of the parahippocampal gyrus $(\mathrm{PHG})$ in case $\mathrm{B}$.

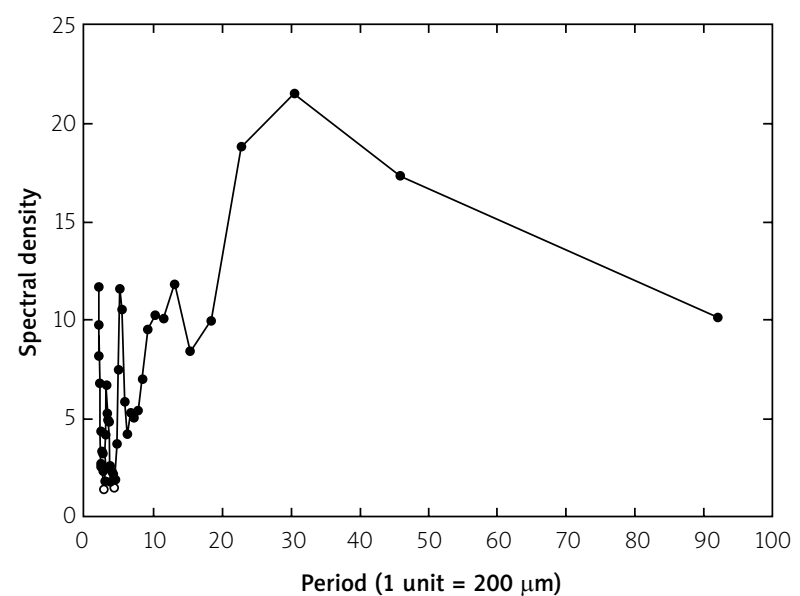

Fig. 4. Spectral density at each period for the data shown in Fig. 2. Three main peaks are evident: 1) at a period of 3 units representing a complete NFT density cycle every 600 to $1200 \mu \mathrm{m}, 2)$ at a period of 15 units representing fluctuation of deposits on a larger scale with cycles recurring every $3000 \mu \mathrm{m}$, and 3) maximum spectral density at a period of 32 units representing an even larger scale of fluctuation repeating every $6400 \mu \mathrm{m}$.

were 'smoothed' to reduce the effect of measurement noise, the spectral density plot was then examined for significant peaks, which indicated the 'periods' of recurring fluctuations, i.e. the number of adjacent $200 \mu \mathrm{m}$ diameter plots necessary to complete one full cycle.

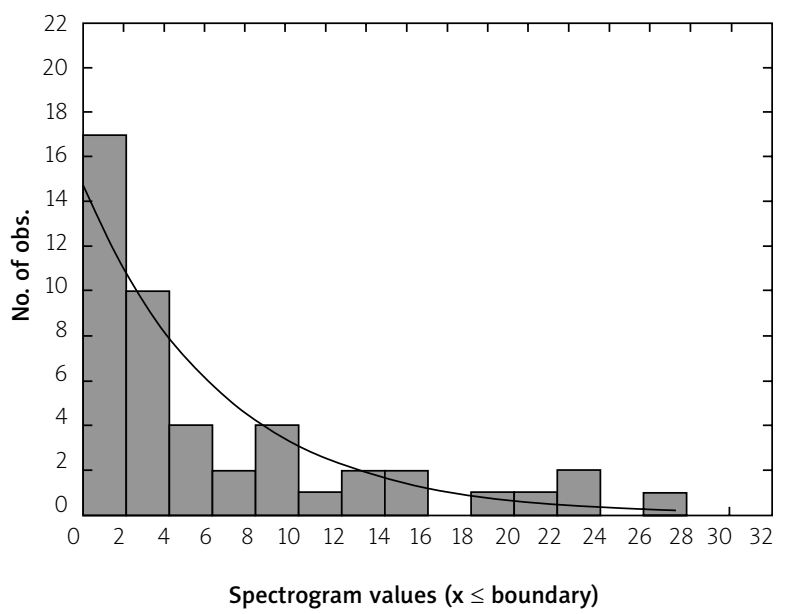

Fig. 3. The frequency distribution of the spectrogram values derived from the data shown in Fig. 2. Goodness of fit of the negative exponential distribution ( $N=92$, Kolmogorov-Smirnov $\mathrm{KS}=0.26, p<0.001$ indicating a significant departure from an exponential distribution).

\section{Results}

An example of Fourier analysis applied to the NFT in the PHG of a single case (Case F) is shown in Figures 2-4. Figure 2 shows the variations in density of the NFT along the gyrus parallel to the pia mater revealing a complex fluctuating pattern and with an individual 'spike' in density at plot 65. Figure 3 shows the frequency distribution of the periodogram (spectrogram) values, a distribution that deviates significantly from the exponential distribution ( $\mathrm{KS}=0.26, p<0.001$ ), indicating the presence of sinusoidal fluctuations. Figure 4 is a plot of the spectral density at each period. A number of peaks or groups of peaks are evident: 1) a group of peaks at periods of 3-6 units representing a complete NFT density cycle with a mean at approximately $900 \mu \mathrm{m}$, 2) at a period of 15 units representing fluctuation of deposits on a larger scale with cycles recurring every $3000 \mu \mathrm{m}$, and 3) maximum spectral density at a period of 32 units representing an even larger scale of fluctuation repeating every $6400 \mu \mathrm{m}$.

A summary of the spectral analyses from all regions and cases is shown in Table II. Of the total of 36 analyses, 8/36 (22\%) were corrected for a linear trend, 7/36 (19\%) exhibited no statistically significant recurring sinusoidal pattern, and in 29/36 (81\%) there was evidence of significant recurring fluctuations of NFT density of at least one frequency. Of the data exhibiting significant frequency components, 
$6 / 29$ (21\%) analyses exhibited a single frequency component (periods $<1000 \mu \mathrm{m}$ in one analysis and $>1000 \mu \mathrm{m}$ in five analyses), 11/29 (38\%) exhibited two frequency components, and in five of these analyses, the first frequency component had a period of $<1000 \mu \mathrm{m}$ and the second $>1000 \mu \mathrm{m}$. In 12/29 (41\%) analyses, three or more frequency components were present. In 20/30 (66\%) cortical regions, the periods were in the range $500-1000 \mu \mathrm{m}$, i.e. the size of the clusters of cells associated with the modular columns of cells that form the cortico-cortical pathways.

The summary statistics for the distribution of the periods of the various frequency components in the AD cases are shown in Table III. In the cerebral cortex, the period of the first frequency component had a mean of $1519 \mu \mathrm{m}$ (range $600-8000 \mu \mathrm{m})$, the second period a mean of $2767 \mu \mathrm{m}$ (range 1000-12800 $\mu \mathrm{m}$ ), and the third frequency component an overall mean period of $4078 \mu \mathrm{m}$ (range $260-6400 \mu \mathrm{m}$ ). Periods of the first two frequency components were generally larger in the hippocampus than in the cerebral cortex.

\section{Discussion}

In the majority of regions analysed, there were significant recurring patterns of NFT density in the upper cortical layers and in three out of the six hippocampus sections. These results are in general agreement with previous studies employing the Poisson distribution and suggest the presence of regularly repeating patterns of NFT formation in the cortex and the hippocampus in some cases in $A D[1,5]$. The commonest spatial pattern observed was a small-scale fluctuation in NFT density, a complete cycle repeating with a mean distance between 500 and $1000 \mu \mathrm{m}$, together with larger-scale patterns repeating at distances greater than $1000 \mu \mathrm{m}$. In some regions, particularly complex patterns were present with three or more frequency components, the largest-scale fluctuations having a mean period of at least $3733 \mu \mathrm{m}$.

The anatomical structure of the cerebral cortex comprises replicated local neural circuits that represent 'columns' or 'modules' [26]. The diameter of the cortical modules is highly variable, depending on the region, and there are specific connections between ordered sets of columns $[19,26]$. First, there is a reciprocal projection between each cortical area and a dorsal nucleus of the thalamus. Second, there
Table II. Periods $(\mu \mathrm{m})$ of the first three frequency components in different brain regions, viz. superior temporal gyrus (STG), superior frontal gyrus (SFG), superior parietal lobe (SPL), lateral occipitotemporal gyrus (LOT), parahippocampal gyrus (PHG), occipital cortex (OC), and CA sectors of the hippocampus $(\mathrm{HC})$ in six Alzheimer's disease (AD) cases. (-) indicate no significant frequency components, KS - Kolmogorov-Smirnov test

\begin{tabular}{|c|c|c|c|c|c|c|}
\hline Case & Region & KS & $\begin{array}{l}\text { Number } \\
\text { of peaks }\end{array}$ & Peak 1 & Peak 2 & Peak 3 \\
\hline \multirow[t]{7}{*}{ A } & STG & 0.39 & 2 & 800 & 2000 & - \\
\hline & SFG & 0.27 & 3 & 800 & 3000 & 6400 \\
\hline & SPL & 0.36 & 4 & 1000 & 1600 & 2600 \\
\hline & LOT & 0.47 & 1 & 8000 & - & - \\
\hline & PHG & 0.49 & 1 & 7400 & - & - \\
\hline & $O C$ & 0.30 & 3 & 800 & 1400 & 4400 \\
\hline & $\mathrm{HC}$ & NS & 0 & - & - & - \\
\hline \multirow[t]{6}{*}{$B$} & STG & 0.22 & 3 & 800 & 1800 & 5000 \\
\hline & SPL & 0.36 & 2 & 1400 & 4400 & - \\
\hline & LOT & 0.26 & 3 & 1000 & 1600 & 2800 \\
\hline & $\mathrm{PHG}$ & 0.25 & 4 & 900 & 3000 & 6400 \\
\hline & OC & 0.23 & 2 & 1600 & 4600 & - \\
\hline & $\mathrm{HC}$ & NS & 0 & - & - & - \\
\hline \multirow[t]{5}{*}{ C } & SFG & 0.21 & 2 & 600 & 2200 & - \\
\hline & LOT & 0.27 & 2 & 600 & 2200 & - \\
\hline & $\mathrm{PHG}$ & 0.26 & 1 & 800 & - & - \\
\hline & $O C$ & 0.32 & 1 & 1000 & - & - \\
\hline & $\mathrm{HC}$ & NS & 0 & - & - & - \\
\hline \multirow[t]{6}{*}{$\mathrm{D}$} & STG & 0.44 & 3 & 800 & 1000 & 3800 \\
\hline & SFG & NS & 0 & - & - & - \\
\hline & SPL & NS & 0 & - & - & - \\
\hline & LOT & 0.17 & 2 & 800 & 1200 & - \\
\hline & $\mathrm{PHG}$ & NS & 0 & - & - & - \\
\hline & $\mathrm{HC}$ & 0.46 & 2 & 1000 & 9800 & - \\
\hline \multirow[t]{6}{*}{$E$} & SFG & 0.38 & 4 & 800 & 2400 & 4200 \\
\hline & SPL & 0.25 & 3 & 600 & 1000 & 4000 \\
\hline & $O C$ & NS & 0 & - & - & - \\
\hline & LOT & 0.26 & 2 & 1000 & 3000 & - \\
\hline & $\mathrm{PHG}$ & 0.53 & 2 & 3000 & 12800 & - \\
\hline & $\mathrm{HC}$ & 0.28 & 3 & 600 & 800 & 2600 \\
\hline \multirow[t]{6}{*}{$\mathrm{F}$} & STG & 0.26 & 4 & 800 & 1200 & 3800 \\
\hline & SFG & 0.46 & 1 & 1800 & - & - \\
\hline & SPL & 0.21 & 2 & 800 & 4100 & - \\
\hline & LOT & 0.23 & 2 & 1000 & 2000 & - \\
\hline & $\mathrm{PHG}$ & 0.27 & 3 & 600 & 1600 & 3800 \\
\hline & $\mathrm{HC}$ & 0.69 & 1 & 8000 & - & - \\
\hline
\end{tabular}


Table III. Summary statistics for the periods of the first, second, and third frequency components (SD - standard deviation, - indicates insufficient data to calculate statistic)

\begin{tabular}{|lccc|}
\hline Peak & Statistic & Cerebral cortex & Hippocampus \\
\hline Peak 1 & Mean $(\mu \mathrm{m})$ & 1519 & 3200 \\
\hline & Range $(\mu \mathrm{m})$ & $600-8000$ & $600-8000$ \\
\hline & SD & 1888 & 416 \\
\hline Peak 2 & Mean $(\mu \mathrm{m})$ & 2767 & 5300 \\
\hline & Range $(\mu \mathrm{m})$ & $1000-12800$ & 6364 \\
\hline & SD & 2536 & 6364 \\
\hline Peak 3 & Mean $(\mu \mathrm{m})$ & 4078 & 2600 \\
\hline & Range $(\mu \mathrm{m})$ & $260-6400$ & - \\
\hline & SD & 1679 & \\
\hline
\end{tabular}

are inputs to the cortex from regulatory systems that have their origin in nuclei located in the basal forebrain and brain stem. As a result, the cortex is interlaced by clusters of fine noradrenergic fibres that repeat at intervals of 30-40 $\mu \mathrm{m}$. Third, homologous neocortical areas, with the exception of the striate cortex and primary somatosensory cortex, are reciprocally linked in both hemispheres via the commissural projections; both the commissural and ipsilateral association fibres terminating in modules 200-500 $\mu \mathrm{m}$ in width, and which alternate in a regular sequence with modules that are relatively free of such connections. Fourth, within a hemisphere, different regions are connected by fibres of the short and long cortico-cortical projections $[13,19]$, the cells of which are also clustered and occur in bands approximately 500-1000 $\mu \mathrm{m}$ in width.

A basic field size width of $200 \mu \mathrm{m}$ cannot detect frequency components that repeat at intervals smaller than this size. Hence, it is not possible to determine whether any NFT were associated with the regulatory systems of the cortex. The smallest frequency component detected had a period consistently between 500 and $1000 \mu \mathrm{m}$. These dimensions suggest a spatial relationship between the NFT and the primary modules of the cortex and which form the cells of origin of the cortico-cortical projections, as postulated in previous studies $[1,5,19,27,35]$. The small number of gyri in which the period was significantly less than $500 \mu \mathrm{m}$ could represent the association of NFT with the commissural projections. In the majority of gyri, more than one spatial frequency component was present, the most common spatial pattern representing fluctuations of NFT repeating every 500-1000 $\mu \mathrm{m}$ and at distances greater than $1000 \mu \mathrm{m}$. In the cerebral cortex, adjacent columns are often organised into larger functional units [26], and the larger-scale fluctuations could represent NFT formation in relation to these groupings of modules. In addition, NFT development could be a dynamic process with coalescence of smaller clusters of NFT to form much larger aggregations as the disease develops [2,35]. In approximately 22\% of regions, there was a distinct linear trend in NFT density parallel to the tissue boundary, which may represent fluctuations on a significantly larger scale, perhaps reflecting the vulnerability of whole or adjacent groups of gyri.

Sinusoidal variations in NFT were also observed within the CA sectors of the hippocampus in three of the six $A D$ cases. These fluctuations may also reflect underlying neuroanatomy and specifically the modular structure of the alvear pathway and perforant path [9]. Degeneration of the hippocampus and its isolation from the rest of the cerebral cortex as a consequence of these processes is likely to be an important factor in developing dementia in $A D$ [13].

The association between cycles of NFT and the modular structure of the cortex has two implications for the pathogenesis of AD. First, the regular cyclic pattern of NFT appears to reflect their development in relation to neurons associated with specific neuroanatomical pathways. This hypothesis is supported by two observations: first, that NFT in AD are highly region specific, layer specific, and cell-type specific [10]; and second, that neurons affected by NFT are functionally related suggesting the spread of degeneration across normal synaptic boundaries [28]. In addition, loss of synaptic markers has been observed in AD, especially in layers III and V of the cerebral cortex, which are likely to contain the majority of cells of origin of the cortico-cortical projections [29]. Hence, the cyclic fluctuations in NFT appear to have their origin in the degeneration of specific anatomical pathways.

Of particular interest is whether the observed fluctuations in density of the NFT reflect the spread of pathogenic tau along neuroanatomical pathways. One of the first studies to suggest that the degeneration in AD could spread across synaptic connections was by Saper et al. [28]. More recent research suggests that pathogenic proteins, including tau, $\alpha$-synuclein, the disease form of prion protein ( $\operatorname{Pr} \mathrm{Psc}^{\mathrm{sc}}$, 
and $A \beta$ may be secreted from cells, enter other cells, and seed small intracellular aggregates within these cells $[18,32]$. Hence, tau could exit cells via exocytosis or secretion and enter a new cell by endocytosis or by interactions with membrane lipids. Transfer may also occur via tunnelling nanotubes (TNT) that connect various neurons [32]. Hence, the spread of tau from cell to cell along neuro-anatomical connections in the cortex could be a significant factor in the observed fluctuations in NFT density detected by Fourier analysis.

In conclusion, spatial analysis of NFT parallel to the pia mater or alveus in the cerebral cortex and hippocampus by Fourier (spectral) analysis reveals sinusoidal fluctuations in density. The fluctuations occur at different scales, the most common pattern being a small-scale sinusoidal fluctuation repeating every 500-1000 $\mu \mathrm{m}$ and a larger-scale pattern repeating at distances greater than $1000 \mu \mathrm{m}$. The data support the hypothesis that NFT formation is related to anatomical connectivity and most specifically to the degeneration of the callosal, cortico-cortical, and cortical-hippocampal projections. Hence, Fourier analysis, as suggested by Bruce et al. [12] and Armstrong and Cairns [9], may be of value in studying the detailed distribution of pathological lesions along or across cortical gyri in neurodegenerative disease and in transgenic models of disease, and further clarify the relative importance of NFT in the pathology of AD.

\section{Disclosure}

The author reports no conflict of interest.

\section{References}

1. Armstrong RA. Is the clustering of neurofibrillary tangles in Alzheimer's patients related to the cells of origin of specific cortico-cortical projections? Neurosci Lett 1993; 160: 57-60.

2. Armstrong RA. The usefulness of spatial pattern analysis in understanding the pathogenesis of neurodegenerative disorders, with special reference to plaque formation in Alzheimer's disease. Neurodegeneration 1993; 2: 73-80.

3. Armstrong RA. Quantifying the pathology of neurodegenerative disorders: quantitative measurements, sampling strategies and data analysis. Histopathology 2003; 42: 521-529.

4. Armstrong RA. Classic $\beta$-amyloid deposits cluster around large diameter blood vessels rather than capillaries in sporadic Alz heimer's disease. Curr Neurovasc Res 2006; 3: 289-294.

5. Armstrong RA. Clustering and periodicity of neurofibrillary tangles in the upper and lower cortical laminae in Alzheimer's disease. Folia Neuropathol 2008; 46: 26-31.
6. Armstrong RA, Myers D, Smith CUM, Cairns NJ, Luthert PJ. Alzheimer's disease: the relationship between the density of senile plaques, neurofibrillary tangles and A4 deposits in human patients. Neurosci Lett 1991; 123: 141-143.

7. Armstrong RA, Myers D, Smith CUM. The spatial patterns of b/ A4 deposit subtypes in Alzheimer's disease. Acta Neuropathol 1993; 86: 36-41.

8. Armstrong RA, Lantos PL, Cairns NJ. What does the study of spatial patterns of pathological lesions tell us about the pathogenesis of neurodegenerative disorders. Neuropathology 2001; 21: 1-12.

9. Armstrong RA, Cairns NJ. Analysis of $\beta$-amyloid $(A \beta)$ deposition in the temporal lobe in Alzheimer's disease using Fourier (spectral) analysis. Neuropathol Appl Neurobiol 2010; 36: 248-257.

10. Braak H, Braak E. The human entorhinal cortex: normal morphology and lamina-specific pathology in various diseases. Neurosci Res 1992; 15: 6-31.

11. Braak H, Braak E, Bohl J. Staging of Alzheimer-related cortical destruction. Eur Neurol 1993; 33: 403-408.

12. Bruce CV, Clinton J, Gentleman SM, Roberts GW, Roystan MC. Quantifying the pattern of beta/A4 amyloid protein distribution in Alzheimer's disease by image analysis. Neuropathol Appl Neurobiol 1992; 18: 125-136.

13. De Lacoste $M$, White CL III. The role of cortical connectivity in Alzheimer's disease pathogenesis: a review and model system. Neurobiol Aging 1993; 14: 1-16.

14. Delaere P, Duyckaerts C, He Y, Piette F, Hauw JJ. Subtypes and differential laminar distribution of b/A4 deposits in Alzheimer's disease: Relationship with the intellectual status of 26 cases. Acta Neuropathol 1991; 81: 328-335.

15. Gallyas F. Silver staining of Alzheimer's neurofibrillary changes by means of physical development. Acta Morphol Acad Sci Hung 1971; 19: 1-8.

16. Glenner GG, Wong CW. Alzheimer's disease and Down's syndrome: sharing of a unique cerebrovascular amyloid fibril protein. Biochem Biophys Res Commun 1984; 122: 1131-1135.

17. Goedert M, Wischik CM, Crowther RA, Walker JE, Klug A. Cloning and sequencing of the CDNA-encoding A core protein of the paired helical filament of Alzheimer-disease-Identification as the microtubule-associated protein tau. Proc Natl Acad Sci USA 1988; 85: 4051-4055.

18. Goedert M, Clavaguera F, Tolnay M. The propagation of prion-like protein inclusions in neurodegenerative diseases. Trends in Neurosciences 2010; 33: 317-325.

19. Hiorns RW, Neal JW, Pearson RCA, Powell TPS. Clustering of ipsilateral cortico-cortical projection neurons to area 7 in the rhesus monkey. Proc R Soc London 1991; 246: 1-9.

20. Hyman BT, Phelps CH, Beach TG, Bigio EH, Cairns NJ, Carrillo MC, Dickson DW, Duyckaerts C, Frosch MP, Masliah E, Mirra SS, Nelson PT, Schneider JA, Thal DR, Thies B, Trojanowski JQ, Vinters HV, Montine TJ. National Institute on Aging-Alzheimer's Association guidelines for the neuropathologic assessment of Alzheimer's disease. Alzheimers Dement 2012; 8: 1-13.

21. Jellinger KA, Bancher C. Neuropathology of Alzheimer's disease: a critical update. J Neural Transm 1998; 54: 77-95.

22. Khatchaturian ZS Diagnosis of Alzheimer's disease. Arch Neurol 1985; 42: 1097-1005. 
23. Kuninaka N, Kawaguchi M, Ogawa M, Sabo A, Arima K, Murayama S, Saito Y. Simplification of the modified Gallyas method. Neuropathology 2014; 35: 10-15.

24. Mirra S, Heyman A, McKeel D, Sumi S, Crain B, Brownlee L, Vogel F, Hughes J, van Belle G, Berg L. The consortium to establish a registry for Alzheimer's disease (CERAD). II. Standardization of the neuropathological assessment of Alzheimer's disease. Neurology 1991; 41: 479-486.

25. Montine TJ, Phelps CH, Beach TG, Bigio EH, Cairns NJ, Dickson DW, Duyckaerts C, Frosch MP, Masliah E, Mirra SS, Nelson PT, Schneider JA, Thal DR, Trojanowski JQ, Vinters HV Hyman BT. National Institute on Aging; Alzheimer's Association. National Institute on Aging-Alzheimer's Association guidelines for the neuropathologic assessment of Alzheimer's disease: a practical approach. Acta Neuropathol 2012; 23: 1-11.

26. Mountcastle VB. An organizing principle for cerebral function: The unit module and the distributed system. In: The Neurosciences. $4^{\text {th }}$ Study Program. Schmitt FO, Worden FG (Eds.). MIT Press, Cambridge 1979; 21-42.

27. Pearson RCA, Esiri MM, Hiorns RW, Wilcock GK, Powell TPS Anatomical correlates of the distribution of the pathologica changes in the neocortex in Alzheimer's disease. Proc Natl Acad Sci USA 1985; 82: 4531-4534.

28. Saper CB, Wainer BH, German DC. Axonal and transneural transport in the transmission of neurological disease: potential role in system degenerations including Alzheimer's disease. Neuroscience 1987; 23: 389-398.

29. Scheff SW, Price DA. Synapse loss in the temporal lobe in Alzheimer's disease. Ann Neurol 1993; 33: 190-199.

30. Shumway RH. Applied statistical time series analysis. Englewood Cliffs, New Jersey, Prentice Hall 1988.

31. Shumway RH, Stoffer DS. Time series analysis and its application. Springer, New York 2000.

32. Steiner JA, Angot E, Brundin P. A deadly spread: cellular mechanisms of a-synuclein transfer. Cell Death Differ 2011; 18: 1425 1433.

33. Sun A, Nguyen XV, Bing G. Comparative analysis of an improved thioflavin-S stain, Gallyas silver stain, and immunohistochemistry for neurofibrillary tangle demonstration in the same sections. J Histochem Cytochem 2002; 50: 463-472.

34. Tierney MC, Fisher RH, Lewis AJ, Zorzitto M, Snow W, Reid D, Nieuwstraten P. The NINCDS-ADRDA work group criteria for the clinical diagnosis of probable Alzheimer's disease. Neurology 1988; 38: 359-364.

35. Van Hoesen GW, Solodkin A. Some modular features of temporal cortex in humans as revealed by pathological changes in Alzheimer's disease. Cerebral Cortex 1993; 3: 465-475. 